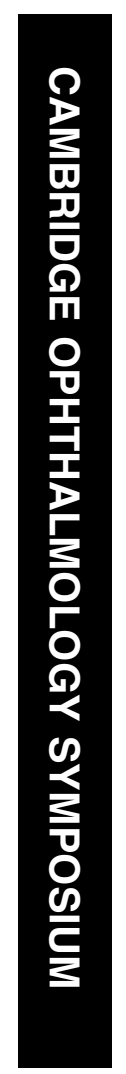

${ }^{1}$ Unit of Ophthalmology, School of Clinical Sciences, University of Liverpool, Merseyside, UK

${ }^{2}$ Eye Service, Aut Even Hospital, Kilkenny, Ireland

Correspondence: CM Sheridan, Ophthalmology, School of Clinical Sciences, University of Liverpool, UCD Duncan Building, Daulby Street, Liverpool, Merseyside L69 3GA, UK Tel: + 4401517064912 ; Fax: + 4401517065802 ; E-mail: c.sheridan@ liverpool.ac.uk

Received: 2 December 2008 Accepted: 2 December 2008

Published online: 23 January 2009

This work was presented in part, at the Cambridge Ophthalmological Symposium, September 2008.

\section{Replacement of the RPE monolayer}

\begin{abstract}
There are numerous scenarios in which replacing the diseased RPE monolayer is an attractive but as yet unrealised goal. The proof of concept that vision can be improved by placing a healthy neuroretina onto a different, healthy, underlying RPE layer is demonstrated in patch graft transplantations. The surgical procedure to relocate the neuroretina is both complex and is hampered by postoperative complications and as such newer replacement procedures are also being investigated including stem cell replacement therapies. Past studies have largely focused on using cell suspensions and have had disappointing outcomes largely due to the lack of control over cellular differentiation, incomplete attachment onto Bruch's membrane and subsequent integration into the existing RPE monolayer. The choice of which cells to transplant is still under investigation and is complicated by factors such as the ease of collection of an adequate sample, rejection following implantation, the age of the cells and ethical issues. In all these situations, however, understanding the mechanisms of cellular differentiation are likely to be prerequisite to future successes.

The current research into replacing the RPE monolayer is briefly discussed with reference to our experiences comparing IPE and RPE cells in an in vitro environment.

Eye (2009) 23, 1910-1915; doi:10.1038/eye.2008.420; published online 23 January 2009
\end{abstract}

Keywords: RPE; AMD; transplant; Iris pigment epithelia; stem cell

\section{Introduction}

A wide ranging variety of diseases at the level of the RPE monolayer make replacing the diseased cells with a healthy monolayer an idealistic goal. The main disease targeted for such therapy has been age-related macular
CM Sheridan', S Mason', DM Pattwell', D Kent ${ }^{1,2}$, I Grierson ${ }^{1}$ and R Williams ${ }^{1}$

degeneration. The recent introduction of anti-VEGF agents (eg, ranibizumab, and so on) have shown great benefit with more than $35 \%$ of patients with classic choroidal neovascularisation (CNV) experiencing a 15-letter visual improvement at 1 year. ${ }^{1}$ The VEGF pathway, however, is only one component of the angiogenic response which is in turn only a part of the overall wound healing response occurring at the macula. ${ }^{2}$ At the time of diagnosis, the subretinal neovascular membranes are already composed of established vascular networks and most of the benefit from anti-VEGF agents may be due to cessation of plasma leakage from incompetent new vessel walls., In addition, with the repeated injections and limited regression of the CNV scar observed, there are a large number of patients for whom no treatment is available. In addition the reality of the much greater problem of non-neovascular AMD has yet to be addressed in any meaningful therapeutic way.

So, while progress in the last decade or so has been outstanding, the scientific community can ill afford to standstill as an ageing epidemic is almost upon us.

There are therefore a number of reasons, which make the idea of replacing the RPE monolayer worthy of even more extensive research. For example, the RPE does not regenerate during adult life and the cells have been exposed to a continuous workload, which as we age, understandably can take its toll. Such examples of this are well documented in the literature including lipofuscin accumulation, altered gene and protein synthesis, oxidatve stress, development of drusen and the accumulation of advanced glycation end-products. ${ }^{5,6}$

The concept of replacing RPE cells has been around for several decades and came to the fore when submacular surgery demonstrated that CNV excision is invariably accompanied with loss of adjacent RPE along with disruption of the underlying Bruch's membrane. ${ }^{7}$ The subsequent loss of RPE is consistent with RPE atrophy and the poor visual outcome that is 
seen after such surgery. ${ }^{8}$ Studies therefore began to focus on whether replacing the lost RPE cells with either homologous (fetal and adult RPE cells) or autologous sources of RPE and IPE cells following post surgical CNV removal could improve the visual outcome. The advantages and disadvantages of each cell source are discussed further below. However, it was the macular relocation and patch graft transplant procedures, which clearly demonstrated a 'proof of principle' for replacing the RPE monolayer. Case selection procedures are being developed using algorithma to assess suitability for macular translocation, which may increase surgical successes. ${ }^{9}$ However, Van Meurs et al and Stanga et al ${ }^{10,11}$ have shown some functional results following patch graft transplant procedures at 1 year and over 2 years followup respectively with improvement in visual function, fixation of the graft using ocular coherence tomography and its vascularisation confirmed by fluorescein and indocyanide green angiography. These procedures used autologous peripheral full-thickness grafts, which were composed of neurosenory retina, RPE, Bruch's membrane, choriocapillaris and choroid and were usually harvested from the midperiphery prior to translocation to the macular following CNV removal. ${ }^{12}$ More recent data suggests that longer than 1 year function may be preserved in some patients with dry AMD. ${ }^{13,14}$ However, although autologous RPE transplantation can in principle restore vision in neovascular AMD, surgical variability and complications still remain high. ${ }^{15}$

\section{Transplantation of adult RPE cells}

Adult RPE have been transplanted into the subretinal space of various animal models as well as human. Methods have included autologous cells, genetically modified RPE cell lines, homologous and heterologous RPE cells as cell suspensions or grown as a monolayer on substrates prior to implantation.

Photoreceptor rescue has been documented by injecting healthy RPE cell suspensions prior to the onset of photoreceptor degeneration in the RCS rat model. Unfortunately, atrophy of photoreceptors was not prevented by transplantation of RPE cells at a later stage of the disease, which may indicate a limited time frame of opportunity for successful transplant procedures. In addition, human RPE cell lines also have been successfully transplanted into the subretinal space of the RCS rats and shown preservation of photoreceptors, visual responses and cortically mediated vision. ${ }^{16,17}$

The environment into which cells are transplanted remains a valid concern. In AMD patients the problems to surmount immediately following CNV excision include the remnants of Bruch's and disrupted choroid as this will govern the microenvironment and thus the fate and success of the cell transplant. ${ }^{12,18}$ Thus, it is important that cells are transplanted with an underlying substrate at the outset. The choice of substrate is covered elsewhere in more detail (see Sheridan et al ${ }^{12}$ ) but in particular it must have excellent biocompatibility, be porous and sustain an intact monolayer of cells. Modifying the patient's own Bruch's membrane may represent an option for some patients but as Bruch's can present itself as either aged, diseased, fragmented or even missing this will be a difficult issue to resolve. Peripheral RPE cells have been harvested and then transplanted, as a cell suspension, into the same eye post CNV removal. ${ }^{19,20}$ Although visual improvement and preservation of retinal thickness have been shown in some patients at follow-up, many other cases have been complicated by extensive PVR, retinal detachment, cell clumping with failure to form an intact monolayer or cell migration.

More recently, 12 patients have received a homologous transplant of RPE cells on a gelatine substrate following surgical removal of a subfoveal CNV membrane, who subsequently underwent immunosuppressive treatment post transplant. ${ }^{21}$ Unfortunately, although the transplanted cells appeared not to be rejected, there was no significant difference between 1 year and preoperative values of best-corrected visual acuity, contrast sensitivity or reading speed. Histological analysis of one patient revealed the RPE transplant did not establish a monolayer and RPE survival was poor. This type of failure may be circumvented if an intact differentiated monolayer on a suitable underlying substrate could be transplanted initially rather than relying on the cells to attach to an aged Bruch's membrane, proliferate, differentiate and integrate with the neural retina before any further photoreceptor loss occurs. Indeed, preventing dedifferentiation of the monolayer will no doubt play a key role in future transplant procedures. Agents that specifically target dedifferentiated cells rather than their differentiated counterparts should be of value to help maintain an intact functioning monolayer. ${ }^{22,23}$ Many studies have shown growth of healthy cells (RPE and IPE) on biodegradable and non-biodegradable artificial substrates and are discussed outside of this review. ${ }^{12}$ We believe that non-degradable artificial substrates hold the greatest promise of achieving such monolayers and satisfying regulatory body approval.

\section{Fetal RPE cells}

The Algvere study was the first to demonstrate some initial success in humans with subretinal transplantation of small monolayer patches of human fetal RPE in AMD 
patients following removal of neovascular membranes. Unfortunately at 3 months post transplantation, retinal function was lost and fixation on the graft was no longer observed. In addition, leakage around the graft was also evident indicating the transplanted cells were being rejected..$^{24}$ Crucial confounding factors such as rejection have also been well documented in most animal models studied and additional complications such as cells clumping or multilayering, rosette formation and photoreceptor loss with resultant drop in visual function have been reported. However, sheets and fetal cell suspensions have been shown to integrate within the monolayer and preserve the normal retinal lamination as well as form some connections with photoreceptors and subsequent visual responsiveness. ${ }^{25-27}$

In addition to transplanting fetal RPE, transplantation of a fetal neuroretina/RPE complex in a 64-year-old woman with retinitis pigmentosa resulted in improvement in visual acuity at 5-year follow-up. ${ }^{28}$ However, this appears to be an isolated case because no such change was observed in any other patient studied. In addition, the patients who could tolerate the triple immunosupression for 6 months showed no apparent immune rejection. Although earlier studies on patients without immunosuppressive drugs which showed no apparent signs of graft rejection at 6 months post transplant demonstrated features associated with rejection that became evident at 1 year post transplant. ${ }^{29}$ This form of operation is unlikely to play a major role in future treatment modalities even if the results had given spectacular improvements in vision as there are serious ethical and logistical issues involved. The ethical issues of using fetal tissue have been widely reported and the logistics of using one fetus per transplant also makes it unfeasible.

\section{Transplantation of IPE cells}

Obtaining an autologous supply of cells, which are relatively easy to harvest, has resulted in numerous studies providing compelling evidence for the use of IPE cells as an alternative cell type for transplantation in AMD. IPE cells can be harvested from a simple surgical procedure, such as an iridectomy ${ }^{30}$ and provide an autologous source of cells thus overcoming the problems associated with immune rejection and long-term immunosupression. In addition, the IPE cells may afford the advantage of being relatively healthier than peripheral RPE, which may to some extent be affected by the underlying disease. ${ }^{12}$ IPE and RPE have been shown to possess a number of key characteristics in common which make successful use of these cells plausible. IPE cells share the same embryonic origin as the RPE (the neuroepithelium), are heavily pigmented, exhibit similar cellular morphological features, express cytokeratin markers (Figure 1) and exhibit a similar mRNA expression profile for cytokines and their receptors relative to RPE. ${ }^{31}$

In addition, we and others ${ }^{31}$ have been able to demonstrate that human IPE have the ability to phagocytose photoreceptor outer segments (POS) in vitro ${ }^{31}$ whereas bovine IPE have been reported to express mRNA for proteins involved in retinol metabolism, such as RPE65, CRALBP and 11-cis-retinol dehydrogenase.

Successful photoreceptor rescue and survival have been demonstrated in a number of animal models following subretinal transplant of a suspension of IPE harvested from peripheral iridectomies. Despite the appearance of interaction with host $\mathrm{POS}^{32-34}$ and phagosomes containing phagocytosed POS fragments being observed in the cytoplasm of transplanted IPE, complications were noted. In particular, areas of multilayering and degeneration were evident. Pilot studies of autologous IPE transplantation in humans
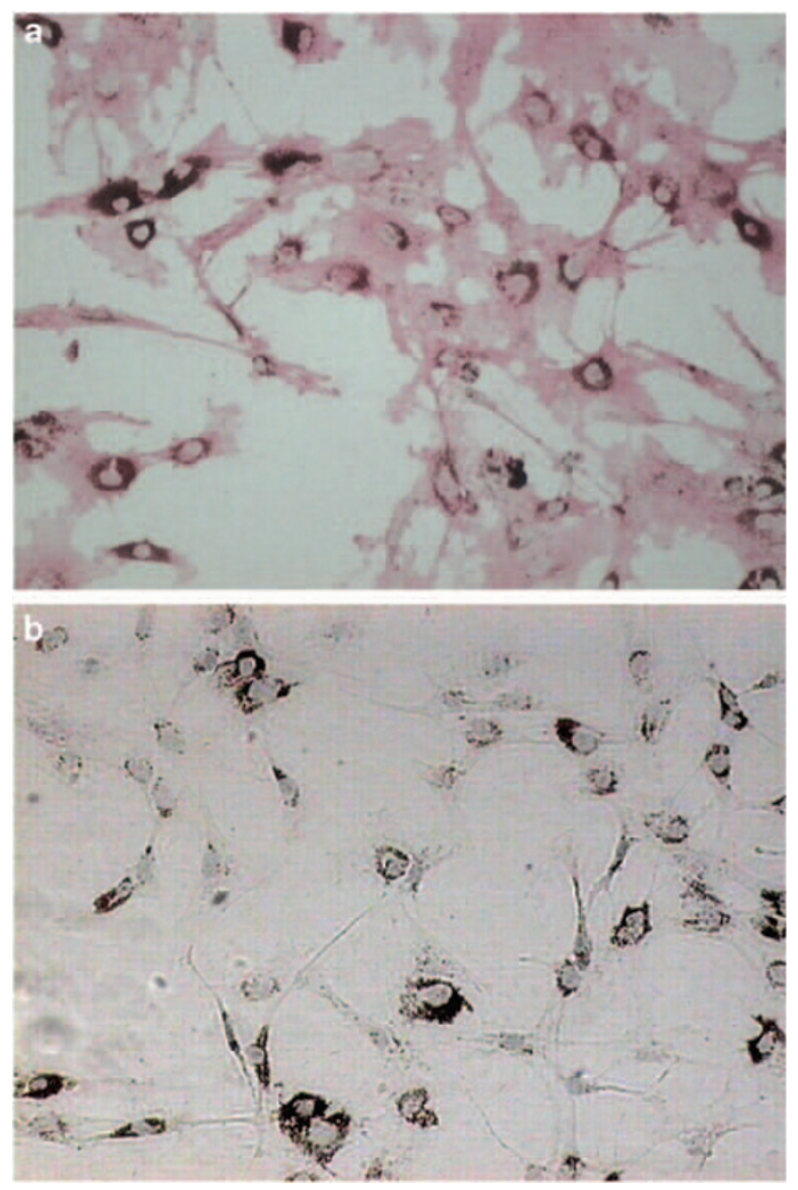

Figure 1 Photomicrographs of preconfluent cultures of primary BIPE cells demonstrating immunoreactivity to the cytokeratin antibody $\mathrm{K} 8.13$ (a) whereas IgG control is negative (b; mag. $\times 100$ ) 
(again using cell suspensions) have shown some promise but results are variable between groups. Central fixation with stabilisation of vision has been documented in neovascular AMD and in some patients with traumatic RPE detachments, ${ }^{30,32,35,36}$ but complications such as those seen in RPE transplantation, including, retinal detachment, PVR, macular pucker and CNV recurrence have been reported. ${ }^{30,32,35}$ It is encouraging that recent follow up studies by Aisenbrey et $a l^{37}$ have reported a stabilisation in visual acuity in $65 \%$ of patients who underwent autologous IPE transplantation after CNV removal and showed no signs of rejection or $\mathrm{CNV}$ recurrence.

As with RPE, IPE cells also have the ability to transdedifferentiate and thus the rationale is that IPE implanted into the subretinal space may transdifferentiate or dedifferentiate into RPE cells or RPE-like phenotypes. However, if the correct environmental cues are not in place then the formation of an intact functioning monolayer is unlikely to occur.

\section{Stem cells}

Human embryonic stem cells have been known to differentiate into RPE cells for a number of years and their differentiation pathway is beginning to be elucidated. ${ }^{38,39}$ The use of ES-RPE cells holds promise in that a large number of cell monolayers could be generated to potentially supply the necessary graft volume required for large-scale therapy, while avoiding any genetic defects inherent in autologous RPE. ${ }^{38,40}$ However, the problem of rejection still needs to be fully solved. Other autologous stem cell sources may circumvent this problem, whether they are from induced pluripotent stem cells or existing adult stem niches. A number of stem cell populations have been identified in adult tissue in both ocular and non-ocular tissue. Their ability to self-renew and differentiate into one or more cell types, has lead to significant interest and efforts into developing new treatments for degenerative diseases. ${ }^{41}$ Several sources of cells have been transplanted into animal models of retinal degenerations with variable levels of success. Many studies have focused on cell integration with the neural retina but in the context of this review we will only discuss those tailored towards RPE integration or replacement. Although migration and integration of the stem cells into the host retina or RPE have been demonstrated with enhanced photoreceptor survival and function, complete integration still as yet, has not been achieved. ${ }^{42-46}$ A greater understanding of the molecular signalling cues and control pathways for specific differentiation into RPE and/or retinal neurones and precise stem cell delivery is needed to appreciate the full potential of stem cell-based treatments. ${ }^{47}$ The recent discovery of retinal stem cell niches that survive into adulthood (at the region of the Ora Serrata) which have the ability to differentiate into neural retinal cells as well as RPE cells may yield a new source of cells which can be differentiated into the relevant cell types prior to transplantation into patients. ${ }^{12,48,49}$ Retinal stem cells (RSCs) have been harvested from the pigmented and non-pigmented epithelium of the ciliary body of rats and humans. ${ }^{48}$ These quiescent cells can be expanded in vitro $^{12,49}$ and are known to express neural progenitor markers such as nestin. ${ }^{12,49}$ Although markers of mature inner and outer retinal cell types have been detected, very low levels of expression of RPE cell markers have been observed $(<1 \%)$ even when the cells were plated onto a laminin substrate. Clearly RSCs by definition must have the potential to differentiate into RPE cells, but this process is only beginning to be elucidated in vitro ${ }^{12,49}$ and must continue to do so if it is to represent a therapeutic option. Further in vivo studies have demonstrated human RSCs transplanted into mice to survive up to 28 days and to integrate into the RPE monolayer as well as other layers of the neuroretina indicating there are a number of environmental queues involved. The eye also contains additional regions (eg, the human iris) that also have been shown to contain cells with stem cell like properties ${ }^{48}$ but unlike the ciliary body-derived RSCs they have yet to be demonstrated to differentiate into RPE cells. ${ }^{50}$

\section{Summary of cell transplantation}

Although the promise of replacing a damaged or diseased RPE monolayer with a new monolayer of cells shows great promise, clinically this potential has yet to be realised. Although stem cell-based therapies have shown some encouraging results, these studies are still at the pre-clinical stage of development. Studies which have made it through to the clinic (such as transplantation of autologous RPE or IPE cells) have shown some promising results but have also demonstrated a number of complications and hurdles that need to be cleared if such a treatment strategy is to have any realistic chances of prolonged success. Consequently, placing the cells as an intact differentiated monolayer on a non-degrading underlying porous substrate may overcome many of the current problems reported for cell transplant procedures such as, cell clustering, dysfunctional multilayering, cell migration, dedifferentiation and intractable PVR.

\section{Acknowledgements}

Dr D Rice for the photomicrograph images and Mr D Brotchie for technical assistance with the images. Funding received from the Dunhill Medical Trust, Fight 
for Sight, Help the Aged, Foundation for the prevention of Blindness.

\section{References}

1 Heier JS, Antoszyk AN, Pavan PR, Leff SR, Rosenfeld PJ, Ciulla TA et al. Ranibizumab for treatment of neovascular age-related macular degeneration: a phase I/II multicenter, controlled, multidose study. Ophthalmology 2006; 113: 642-644.

2 Kent D, Sheridan C. Choroidal neovascularization: a wound healing perspective. Mol Vis 2003; 9: 747-755.

3 Tezel TH, Kaplan HJ. Are intravitreal anti-VEGF antibodies safe? Ocul Immunol Inflamm 2007; 15: 1-2.

4 Tezel TH, Del Priore LV, Berger AS, Kaplan HJ. Adult retinal pigment epithelial transplantation in exudative age-related macular degeneration. Am J Ophthalmol 2007; 143: 584-595.

5 Ambati J, Ambati BK, Yoo SH, Ianchulev S, Adamis AP. Age-related macular degeneration: etiology, pathogenesis, and therapeutic strategies. Surv Ophthalmol 2003; 48: 257-293.

6 Forrester JV, Dick AD, McMenamin PG, Lee WR. The eye: basic sciences in practice. W.B. Saunders: London, 2002.

7 Grossniklaus HE, Miskala PH, Green WR, Bressler SB, Hawkins BS, Toth C et al. Histopathologic and ultrastructural features of surgically excised subfoveal choroidal neovascular lesions: submacular surgery trials report no. 7. Arch Ophthalmol 2005; 123: 914-921.

8 Bressler NM, Bressler SB, Childs AL, Haller JA, Hawkins $\mathrm{BS}$, Lewis $\mathrm{H}$ et al. Surgery for hemorrhagic choroidal neovascular lesions of age-related macular degeneration: ophthalmic findings: SST report no. 13. Ophthalmology 2004; 111: 1993-2006.

9 Uppal G, Milliken A, Lee J, Acheson J, Hykin P, Tufail A et al. New algorithm for assessing patient suitability for macular translocation surgery. Clin Experiment Ophthalmol 2007; 35: 448-457.

10 van Meurs JC, Van Den Biesen PR. Autologous retinal pigment epithelium and choroid translocation in patients with exudative age-related macular degeneration: shortterm follow-up. Am J Ophthalmol 2003; 136: 688-695.

11 Stanga PE, Kychenthal A, Fitzke FW, Halfyard AS, Chan R, Bird AC et al. Retinal pigment epithelium translocation after choroidal neovascular membrane removal in age-related macular degeneration. Ophthalmology 2002; 109: 1492-1498.

12 Sheridan CM, Krishna Y, Williams RL, Mason S, Wong D, Heimann $\mathrm{H}$ et al. Transplantation in the treatment of age related macular degeneration: past present and future directions. Expert Rev Ophthalmol 2007; 2: 497-511.

13 Heussen FM, Fawzy NF, Joeres S, Lux A, Maaijwee K, Meurs JC et al. Autologous translocation of the choroid and RPE in age-related macular degeneration: 1-year follow-up in 30 patients and recommendations for patient selection. Eye 2008; 22: 799-807.

14 Joussen AM, Joeres S, Fawzy N, Heussen FM, Llacer H, van Meurs JC et al. Autologous translocation of the choroid and retinal pigment epithelium in patients with geographic atrophy. Ophthalmology 2007; 114: 551-560.

15 MacLaren RE, Uppal GS, Balaggan KS, Tufail A, Munro PM, Milliken $\mathrm{AB}$ et al. Autologous transplantation of the retinal pigment epithelium and choroid in the treatment of neovascular age-related macular degeneration. Ophthalmology 2007; 114: 561-570.
16 Coffey PJ, Girman S, Wang SM, Hetherington L, Keegan DJ, Adamson $\mathrm{P}$ et al. Long-term preservation of cortically dependent visual function in RCS rats by transplantation. Nat Neurosci 2002; 5: 53-56.

17 Lund RD, Adamson P, Sauve Y, Keegan DJ, Girman SV, Wang $S$ et al. Subretinal transplantation of genetically modified human cell lines attenuates loss of visual function in dystrophic rats. Proc Natl Acad Sci USA 2001; 98: 9942-9947.

18 da Cruz L. New developments in age-related macular degeneration. Community Eye Health 2008; 21: 50.

19 Binder S, Krebs I, Hilgers RD, Abri A, Stolba U, Assadoulina A et al. Outcome of transplantation of autologous retinal pigment epithelium in age-related macular degeneration: a prospective trial. Invest Ophthalmol Vis Sci 2004; 45: 4151-4160.

20 van Meurs JC, ter Averst E, Hofland LJ, van Hagen PM, Mooy CM, Baarsma GS et al. Autologous peripheral retinal pigment epithelium translocation in patients with subfoveal neovascular membranes. Br J Ophthalmol 2004; 88: 110-113.

21 Tezel TH, Del Priore LV, Berger AS, Kaplan HJ. Adult retinal pigment epithelial transplantation in exudative age-related macular degeneration. Am J Ophthalmol 2007; 143: 584-595.

22 Kent D, Sheridan CM, Tomkinson HA, White SJ, Hiscott P, $\mathrm{Yu}$ L et al. Edible mushroom (Agaricus bisporus) lectin inhibits human retinal pigment epithelial cell proliferation in vitro. Wound Repair Regen 2003; 11: 285-291.

23 Kent D, Sheridan C, Tomkinson HA, White S, Hiscott P, Grierson I. Edible mushroom (Agaricus bisporus) lectin modulates human retinal pigment epithelial cell behaviour in vitro. Exp Eye Res 2003; 76: 213-219.

24 Algvere PV, Gouras P, Dafgard KE. Long-term outcome of RPE allografts in non-immunosuppressed patients with AMD. Eur J Ophthalmol 1999; 9: 217-230.

25 Aramant RB, Seiler MJ. Progress in retinal sheet transplantation. Prog Retin Eye Res 2004; 23: 475-494.

26 Del Priore LV, Ishida O, Johnson EW, Sheng Y, Jacoby DB, Geng $\mathrm{L}$ et al. Triple immune suppression increases shortterm survival of porcine fetal retinal pigment epithelium xenografts. Invest Ophthalmol Vis Sci 2003; 44: 4044-4053.

27 Sauve Y, Girman SV, Wang S, Keegan DJ, Lund RD. Preservation of visual responsiveness in the superior colliculus of RCS rats after retinal pigment epithelium cell transplantation. Neuroscience 2002; 114: 389-401.

28 Radtke ND, Aramant RB, Petry HM, Green PT, Pidwell DJ, Seiler MJ. Vision improvement in retinal degeneration patients by implantation of retina together with retinal pigment epithelium. Am J Ophthalmol 2008; 146: 172-182.

29 Radtke ND, Aramant RB, Seiler MJ, Petry HM, Pidwell D. Vision change after sheet transplant of fetal retina with retinal pigment epithelium to a patient with retinitis pigmentosa. Arch Ophthalmol 2004; 122: 1159-1165.

30 Lappas A, Foerster AM, Weinberger AW, Coburger S, Schrage NF, Kirchhof B. Translocation of iris pigment epithelium in patients with exudative age-related macular degeneration: long-term results. Graefes Arch Clin Exp Ophthalmol 2004; 242: 638-647.

31 Thumann G. Development and cellular functions of the iris pigment epithelium. Surv Ophthalmol 2001; 45: 345-354.

32 Abe T, Yoshida M, Tomita H, Kano T, Sato M, Wada Y et al. Auto iris pigment epithelial cell transplantation in patients with age-related macular degeneration: short-term results. Tohoku J Exp Med 2000; 191: 7-20. 
33 Crafoord S, Geng L, Seregard S, Algvere PV. Photoreceptor survival in transplantation of autologous iris pigment epithelial cells to the subretinal space. Acta Ophthalmol Scand 2002; 80: 387-394.

34 Semkova I, Kreppel F, Welsandt G, Luther T, Kozlowski J, Janicki $\mathrm{H}$ et al. Autologous transplantation of genetically modified iris pigment epithelial cells: a promising concept for the treatment of age-related macular degeneration and other disorders of the eye. Proc Natl Acad Sci USA 2002; 99: 13090-13095.

35 Lappas A, Weinberger AW, Foerster AM, Kube T, Rezai KA, Kirchhof B. Iris pigment epithelial cell translocation in exudative age-related macular degeneration. A pilot study in patients. Graefes Arch Clin Exp Ophthalmol 2000; 238: 631-641.

36 Thumann G, Aisenbrey S, Schraermeyer U, Lafaut B, Esser $\mathrm{P}$, Walter $\mathrm{P}$ et al. Transplantation of autologous iris pigment epithelium after removal of choroidal neovascular membranes. Arch Ophthalmol 2000; 118: 1350-1355.

37 Aisenbrey S, Lafaut BA, Szurman P, Hilgers RD, Esser P, Walter $\mathrm{P}$ et al. Iris pigment epithelial translocation in the treatment of exudative macular degeneration: a 3-year follow-up. Arch Ophthalmol 2006; 124: 183-188.

38 Vugler A, Lawrence J, Walsh J, Carr A, Gias C, Semo M et al. Embryonic stem cells and retinal repair. Mech Dev 2007; 124: 807-829.

39 Vugler A, Carr AJ, Lawrence J, Chen LL, Burrell K, Wright A et al. Elucidating the phenomenon of HESC-derived RPE: Anatomy of cell genesis, expansion and retinal transplantation. Exp Neurol 2008; 214(2): 347-361.

40 da CL, Chen FK, Ahmado A, Greenwood J, Coffey P. RPE transplantation and its role in retinal disease. Prog Retin Eye Res 2007; 26: 598-635.

41 Laurent G. Directed issue on stem cells. Int J Biochem Cell Biol 2004; 36: 553.

42 Enzmann V, Howard RM, Yamauchi Y, Whittemore SR, Kaplan HJ. Enhanced induction of RPE lineage markers in pluripotent neural stem cells engrafted into the adult rat subretinal space. Invest Ophthalmol Vis Sci 2003; 44: 5417-5422.

43 Young MJ, Ray J, Whiteley SJ, Klassen H, Gage FH. Neuronal differentiation and morphological integration of hippocampal progenitor cells transplanted to the retina of immature and mature dystrophic rats. Mol Cell Neurosci 2000; 16: 197-205.

44 Harris JR, Brown GA, Jorgensen M, Kaushal S, Ellis EA, Grant $\mathrm{MB}$ et al. Bone marrow-derived cells home to and regenerate retinal pigment epithelium after injury. Invest Ophthalmol Vis Sci 2006; 47: 2108-2113.

45 Klassen HJ, Ng TF, Kurimoto Y, Kirov I, Shatos M, Coffey P et al. Multipotent retinal progenitors express developmental markers, differentiate into retinal neurons, and preserve light-mediated behavior. Invest Ophthalmol Vis Sci 2004; 45: 4167-4173.

46 Qiu G, Seiler MJ, Mui C, Arai S, Aramant RB, de Juan Jr E et al. Photoreceptor differentiation and integration of retinal progenitor cells transplanted into transgenic rats. Exp Eye Res 2005; 80: 515-525.

47 Limb GA, Daniels JT, Cambrey AD, Secker GA, Shortt AJ, Lawrence JM et al. Current prospects for adult stem cell-based therapies in ocular repair and regeneration. Curr Eye Res 2006; 31: 381-390.

48 Coles BL, Angenieux B, Inoue T, Del Rio-Tsonis K, Spence JR, McInnes RR et al. Facile isolation and the characterization of human retinal stem cells. Proc Natl Acad Sci USA 2004; 101: 15772-15777.

49 Sheridan CM, Mason S, Williams RL, Grierson I. Isolation and culture of retinal stem cells for the potential treatment of Age-related Macular Degeneration. Clin Experiment Ophthalmol 2008; 36(1): 523.

50 Sheridan CM, Krishna Y, Williams RL, Mason S, Wong D, Heimann $\mathrm{H}$ et al. Transplantation in the treatment of age related macular degeneration: past present and future directions. Expert Rev Ophthalmol 2007; 2: 497-511. 